DOI: http://dx.doi.org/10.12957/demetra.2015.14142

\title{
Ocorrência de Coliformes Totais e Termotolerantes em pastéis fritos vendidos em bares no centro de Curitiba-PR
}

\section{Occurrence of Total and Thermotolerant Coliforms in fried pastries sold in bars in downtown Curitiba-PR, Brazil}

\author{
Willian Barbosa Sales' \\ Juliana Ferreira Tunala² \\ Jannaina Ferreira de Melo Vasco ${ }^{3}$ \\ Edilceia Domingues do Amaral Ravazzani4 \\ Cristiano Caveic̃o $0^{5}$ \\ ' Centro Universitário Autônomo do Brasil, Escola \\ de Saúde. Curitiba-PR, Brasil. \\ Correspondência / Corrrespondence \\ Willian Barbosa Sales \\ E-mail: sallesbio@hotmail.com / \\ willianbarbosasales@gmail.com
}

\section{Resumo}

Alimentos vendidos em bares que às vezes não possuem condições higiênico-sanitárias adequadas para produzi-los, manipulá-los e vendê-los, acabam sendo contaminados por micro-organismos que podem ser nocivos à saúde, causando infecções e intoxicações alimentares. O principal objetivo do estudo é identificar a presença de coliformes totais e termotolerantes em pastéis fritos vendidos em bares no centro de Curitiba-PR. A abordagem foi quantitativa, com participação de 20 estabelecimentos escolhidos aleatoriamente. As análises microbiológicas foram realizadas utilizando o método Petrifilm para contagem das unidades formadoras de colônias e identificação dos micro-organismos. Constatou-se a presença de coliformes totais em 17 amostras analisadas, sendo que a amostra com maior contaminação apresentou 41 unidades formadoras de colônias. Nenhuma das 20 amostras apresentou coliformes termotolerantes, o que deixa os pastéis de carne moída de acordo com os padrões estabelecidos pela Resolução RDC n. 12/2001. Com base nos resultados, a elevada concentração de coliformes totais sugere maior cuidado nas boas práticas de fabricação e manipulação, a fim de evitar a deterioração e propagação de doença pelo alimento.

Palavras-chave: Manipulação de Alimentos. Microbiologia de Alimentos. Doenças Transmitidas por Alimentos. Grupo Coliforme. 


\section{Abstract}

Food sold in bars, which sometimes do not have adequate sanitary conditions to produce, handle and sell them, end up being contaminated by micro-organisms that may be harmful to health, causing infections and food poisoning. The main objective of the study is to identify the presence of total and fecal coliforms in fried pastry sold in bars in downtown Curitiba-PR, Brazil. The study had quantitative approach and included 20 randomly chosen establishments. Microbiological analyzes were performed using the Petrifilm method for counting colony forming units and identification of microorganisms. There were total coliforms in 17 samples, and the sample with the highest contamination presented 41 colony forming units. None of the 20 samples showed fecal coliform, which makes pastries of ground beef in accordance with the standards established by Resolution RDC 12/2001. Based on the results, the high concentration of total coliforms suggests greater caution in good manufacturing practices and handling to avoid deterioration and disease spread by food.

Key words: Food Handling. Food Microbiology. Foodborne Diseases. Coliform Group.

\section{Introdução}

A falta de tempo e a pressa fazem com que tudo seja feito com rapidez, incluindo a alimentação, e isso acaba resultando na busca do alimento prático, de fácil acesso e baixo custo - perfil de alimentos encontrados em bares, lanchonetes, feiras e vendedores ambulantes nas ruas dos grandes centros urbanos. ${ }^{1,2} \mathrm{O}$ grande problema desses alimentos é a desconhecida procedência ou a falta de informação sobre as condições a que esses alimentos foram submetidos durante o preparo, como salgados fritos e assados, pastéis, tortas, bolos, sanduíches, entre outros, muitas vezes preparados no próprio estabelecimento. ${ }^{3,4}$

Existem várias etapas durante a produção de alimentos processados, e nelas os alimentos são expostos à contaminação por diferentes micro-organismos, provenientes da manipulação, contato com equipamentos e utensílios sem higienização adequada, ou também do ambiente. Cada uma dessas etapas pode permitir a sobrevivência e crescimento de micro-organismos que podem levar a infeções ou intoxicações alimentares, ${ }^{5}$ causadas por fungos, bactérias, vírus, parasitas patogênicos e toxinas microbianas. As bactérias são responsáveis por aproximadamente $90 \%$ dos casos, e as 
mais encontradas são Escherichia coli, Listeria monocytogenes, Salmonella spp., Staphylococcus aureus e Yersinia enterocolitica. ${ }^{6}$

A pesquisa de coliformes nos alimentos é utilizada como indicador das condições higiênicosanitárias do ambiente onde foi produzido e do indivíduo que manipulou o alimento. A presença dos coliformes totais e termotolerantes em alimentos indica que houve contato direto ou indireto com material fecal. Essa pesquisa é feita seguindo os padrões estabelecidos pela Resolução RDC n⿳⺈ 12, de 02 de janeiro de 2001.7,8

O grupo dos coliformes totais consiste em bactérias na forma de bastonetes gram-negativos, não esporuladas, aeróbios ou anaeróbios facultativos, com capacidade de fermentar a lactose produzindo gás, em 24 a 48 horas a 35ํㅡ. O grupo dos coliformes termotolerantes tem a mesma definição dos coliformes totais, porém restringem-se a bactérias capazes de fermentar a lactose produzindo gás, em 24 horas a 44,5-45,5ํㅡ. As bactérias pertencentes a esses grupos são da família Enterobacteriaceae, predominantemente, bactérias dos gêneros Escherichia spp., Enterobacter spp., Citrobacter spp. e Klebsiella spp., sendo encontradas nas fezes, vegetação e no solo, com exceção apenas da Escherichia coli, presente apenas no trato intestinal do homem e animais homeotérmicos. ${ }^{9-11}$

A carne é importante fonte de proteínas que ajuda a suprir as necessidades nutricionais humanas e fornece micronutrientes, sendo uma das principais fontes de ferro, vitaminas do complexo B, principalmente B12, e zinco. No entanto, a carne também é um excelente meio para a proliferação de micro-organismos, em especial a carne moída, muito usada para fazer sanduíches, pastéis, salgados e outros pratos. Esta oferece maior risco de contaminação por apresentar maior superfície de contato, sofrer maior manipulação e possuir alta atividade de água e $\mathrm{pH}$ adequado para crescimento e proliferação de bactérias de interesse alimentar, devido à capacidade de causar doenças. ${ }^{12}$

As doenças transmitidas por alimentos (DTAs) são adquiridas pela ingestão de água ou alimentos contaminados por agentes químicos ou biológicos. São muito comuns, mas muitos casos não são notificados, pois são confundidos com outras patologias, como gripes ou indigestão. Os principais sintomas são vômitos, diarreia, dor de estômago, náusea e febre. No período de 2000 a 2011, de acordo com dados da Secretaria de Vigilância em Saúde, foram notificados 8.663 surtos de DTAs, que afetaram 163.425 brasileiros, dentre os quais 112 foram a óbito. As DTAs podem causar complicações ao indivíduo, sendo responsáveis por alto número de hospitalizações todos os anos, com quadros irreversíveis. ${ }^{13-15}$

O presente trabalho tem como objetivo avaliar a qualidade microbiológica dos pastéis de carne moída vendidos em bares do centro da cidade de Curitiba-PR, pela determinação da presença de coliformes totais e termotolerantes. 


\section{Metodologia}

Foram coletadas 20 amostras de pastel de carne moída, com média de aproximadamente 100 gramas cada um, em estabelecimentos da região central de Curitiba-PR. As coletas foram realizadas no período de maio a junho de 2014. Como critérios de inclusão, foram avaliados estabelecimentos comerciais (bares) que tinham como produto de comercialização pastel de carne moída, estabelecimentos comerciais (bares) que estavam credenciados pela Prefeitura Municipal de Curitiba pelo setor de Vigilância Sanitária com licença sanitária válida. Como critério de exclusão, foram considerados: pastel de carne moída vendido de um dia para o outro; pastel de carne moída estourado na hora da fritura e pastel de carne moída cujas propriedades organolépticas tenham sido alteradas no momento da compra, como forma e consistência.

Após a aquisição das amostras, estas foram acondicionadas em caixa de material isotérmico com gelo, de modo que foram conservadas as mesmas características microbiológicas da comercialização. Em seguida, foi realizado o transporte imediato ao Laboratório de Microbiologia do Centro Universitário Autônomo do Brasil, para execução das análises microbiológicas. Após a determinação, foram relacionados os resultados das análises microbiológicas, com a RDC nํㅜ 12/2001 de microbiologia de alimentos para controle de qualidade e segurança alimentar.

Todo o material utilizado para o processamento das amostras estava estéril e toda a operação foi realizada próxima a um bico de Bunsen com a chama a meia altura em uma câmara de fluxo laminar. As análises microbiológicas foram realizadas pelo método Petrifilm® (3M Company) método oficial da Association of Official Analytical Chemists (AOAC). O método Petrifilm® realiza uma modificação na coloração para a contagem de unidades formadoras de colônia (UFCs) em placas, sendo composto por dois filmes estéreis reidratáveis, impregnados pelo meio de cultura que contém os nutrientes do ágar vermelho violeta bile (VRBA), um agente gelificante solúvel em água fria, um indicador de atividade glucuronidase (5-bromo-4cloro-3indolil- $\beta$-D-glicuronídeo) e um indicador tetrazólico. ${ }^{16,17}$

No laboratório, foram pesadas 25 gramas de cada pastel de carne moída e adicionadas a 225 $\mathrm{ml}$ de água peptona estéril, que foram assim liquidificadas e homogeneizadas por dez minutos, originando a amostra. Após esse processo, com a amostra foram realizadas três diluições seriadas $\left(10^{1}-10^{3}\right)$ compostas por $9 \mathrm{ml}$ de água peptonada e $1 \mathrm{ml}$ da amostra. Com o auxílio de uma pipeta, foi inoculado $1 \mathrm{ml}$ da terceira diluição no filme inferior da placa Petrifilm ${ }^{\circledR}$, e recoberto com o filme superior; em seguida, após a solidificação do gel, as placas foram incubadas em 35ํㅡ por 48 horas para o desenvolvimento das colônias. ${ }^{16,17}$

Para a determinação da presença de coliformes totais e termotolerantes presentes nas amostras, foram realizadas as contagens das UFCs, onde colônias de coliformes totais que cresceram na placa Petrifilm ${ }^{\circledR}$ produziram ácido, que fez com que o indicador de $\mathrm{pH}$ tornasse a cor do gel para um 
vermelho escuro e a produção de gás que ficou retido ao redor das colônias vermelhas, indicando a presença de coliformes totais. Para identificação de coliformes termotolerantes (Escherichia coli), ocorreu a formação de colônias azuis ou vermelho-azuladas, associadas a bolhas de gás.

A glicoronidase produzida pela Escherichia coli reage com o corante indicador na placa, formando um precipitado azul em torno da colônia. Não foram consideradas e contadas colônias que cresceram na borda de espuma da placa, pois estas não estão sob a influência seletiva do meio. ${ }^{16,17}$ Os resultados foram registrados e analisados de forma descritiva simples, através de um banco de dados elaborado com auxílio do programa Microsoft $E X C E L^{\circledR}$, sendo os resultados tabulados e apresentados na forma de gráficos.

\section{Resultados}

É muito importante realizar a análise microbiológica feita neste estudo, para os alimentos fritos de consumo imediato, como o pastel de carne moída. É possível avaliar a qualidade do produto que está sendo comercializado, assegurando aos consumidores que os produtos estão aptos para consumo. ${ }^{18} \mathrm{Na}$ figura 1, estão representados os valores de UFCs de coliformes totais presentes nas amostras.

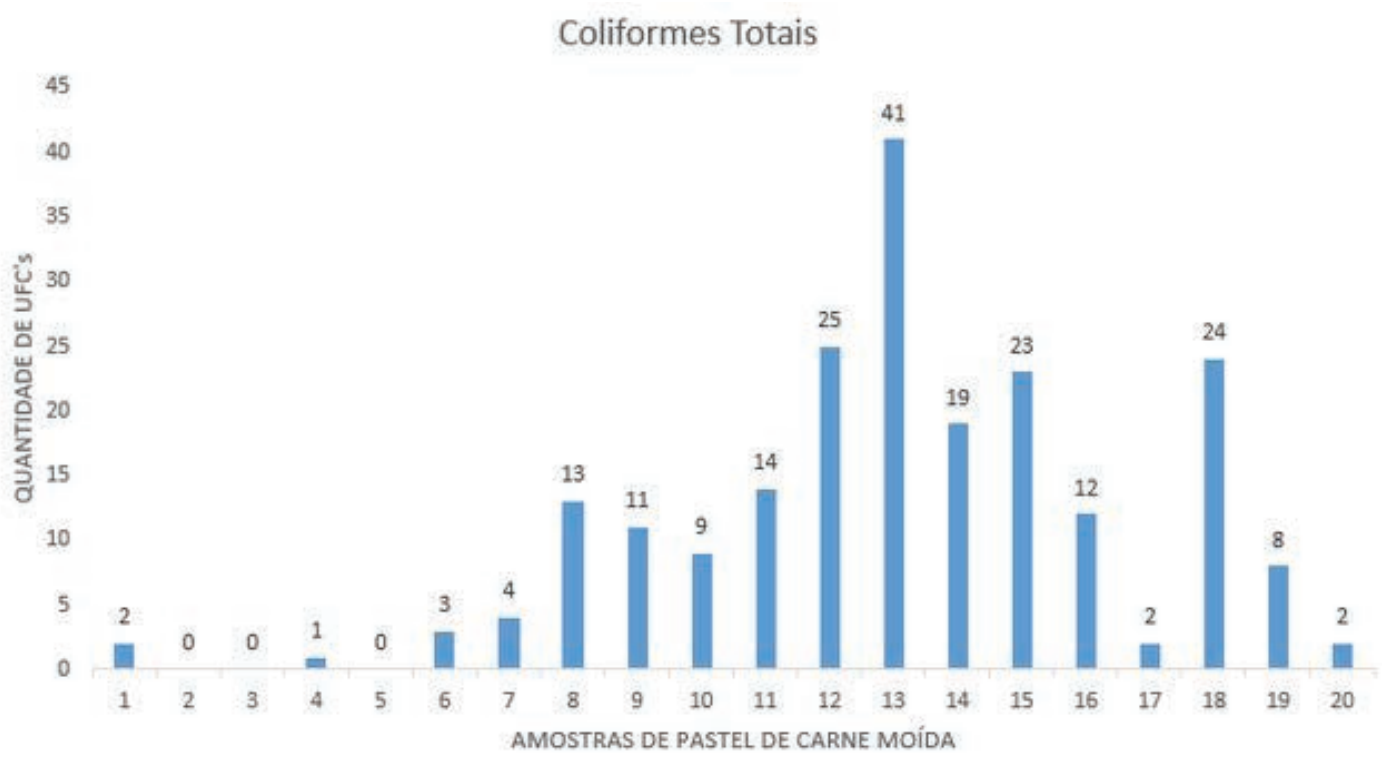

Figura 1. Determinação da presença de coliformes totais em pastéis fritos de carne moída, adquiridos em bares do centro de Curitiba no período de maio a julho de 2014. 


\section{Discussão}

A legislação em vigor não estabelece parâmetros microbiológicos para coliformes totais. As amostras foram submetidas a esta análise para se conhecer a carga microbiana, e assim avaliar as condições higiênico-sanitárias dos pastéis de carne moída, sabendo que esses parâmetros refletem a qualidade do alimento, a higiene do ambiente e o cuidado com que os manipuladores manuseiam os alimentos. ${ }^{18-20}$ A presença das bactérias do grupo coliformes, principalmente os coliformes totais, está relacionada a práticas inadequadas de manipulação, processamento, procedimentos e sanitização na fabricação do produto. ${ }^{20}$ No entanto, produtos cárneos que possuem concentração bacteriana em torno de $10 \mathrm{UFC} / \mathrm{g}$ já possuem suas propriedades organolépticas comprometidas, podendo fornecer risco à saúde do consumidor. ${ }^{10}$

Observou-se, neste estudo, que em apenas três amostras não foram encontradas bactérias desse grupo. O maior valor encontrado foi verificado na amostra de número 13, onde foram contadas 41 UFCs. Nenhuma das 20 amostras analisadas estava contaminada com coliformes termotolerantes, o que deixa os pastéis de carne moída de acordo com os padrões estabelecidos pela Resolução RDC no 12, de 02 de janeiro de 2001. Leva-se em consideração, no entanto, que o produto analisado só foi comercializado após passar por um processo de cocção a temperaturas superiores a $60^{\circ} \mathrm{C} .{ }^{17}$

Esses resultados são semelhantes à pesquisa de Brito, ${ }^{21}$ realizada em Juazeiro do Norte-CE, na qual se verificou que os níveis de coliformes obtidos nas amostras de hambúrgueres e cachorrosquentes comercializados por vendedores ambulantes no município estiveram dentro dos padrões normais da legislação. Também é possível comparar os resultados obtidos por Pierozan et al., ${ }^{22} \mathrm{em}$ pesquisa realizada no Lago Municipal de Toledo-PR, avaliando a qualidade higiênico-sanitária de cachorros-quentes comercializados por vendedores ambulantes. Não foi constatada a presença de coliformes termotolerantes em nenhuma das seis amostras analisadas, mas quanto ao grupo dos coliformes totais, cinco amostras apresentaram crescimento desse grupo de micro-organismos.

Entretanto, em estudo realizado por Bezerra et al..$^{23}$ em Cuiabá-MT, observou-se que 11,4\% das amostras de sanduíches comercializados nas ruas, ficaram fora dos valores permitidos pela legislação brasileira. A presença desses coliformes no alimento avalia a qualidade higiênico-sanitária tanto da manipulação, quanto do preparo, e verifica se ele está apto para consumo. ${ }^{18}$

A contaminação desse tipo de alimento pode ter várias fontes, como locais de armazenamento, transporte, equipamentos moedores, manipuladores, ambiente, recipientes e utensílios. Segundo a Instrução Normativa no 83, de 21 de novembro de 2003, do Ministério de Agricultura, Pecuária e Abastecimento, ${ }^{24}$ a carne moída resfriada deve ser mantida à temperatura de $0^{\circ}-4^{\circ} \mathrm{C}$, e a carne moída congelada à temperatura máxima de -18C durante o armazenamento. Porém, pela elevada carga microbiana presente nas amostras analisadas neste estudo, pode-se presumir que possam ter ocorridos falhas em algumas partes desses processos. 
A moagem da carne é um dos principais fatores que favorecem a contaminação e a proliferação de micro-organismos. Por ser a carne um produto muito consumido e por apresentar fatores que possibilitam o desenvolvimento e proliferação de micro-organismos deterioradores e patogênicos, é preciso haver grande controle da qualidade higiênico-sanitária em todas as etapas de seu processamento e manipulação. ${ }^{25-27}$

A Resolução RDC no 216, de 15 de setembro de 2004, que dispõe sobre o Regulamento Técnico de Boas Práticas para Serviços de Alimentação, ${ }^{28}$ vem corroborar o presente estudo, no sentido das necessidades da higienização das instalações, equipamentos, móveis e utensílios, a fim de evitar a propagação de micro-organismos. A área de preparação dos alimentos deve ser higienizada quantas vezes forem necessárias e imediatamente ao término do trabalho. A higiene dos manipuladores deve ser assegurada através de registros, supervisionando-se periodicamente a higiene pessoal e a manipulação adequada dos alimentos para se evitar as DTAs. O tratamento térmico de cocção deve ser levado em consideração, bem como a relação entre tempo e temperatura, para assegurar a qualidade higiênico-sanitária e a segurança alimentar. ${ }^{28}$

\section{Conclusão}

Os resultados obtidos evidenciaram que a qualidade microbiológica dos pastéis atende ao preconizado pela Vigilância Sanitária, quando comparados à RDC ํㅡㄹ 12/2001. No entanto, os elevados valores encontrados de coliformes totais evidenciam que o produto pode fornecer risco ao consumidor. Embora não existam valores de referência preconizados para coliformes totais, sua presença no alimento pode sugerir que este foi preparado e manipulado em ambiente impróprio para consumo, o que reduz a vida útil do alimento.

Do ponto de vista da Agência Nacional de Vigilância Sanitária (ANVISA), a sociedade deve ter a seu alcance alimentos seguros, de boa qualidade, dentro dos padrões preestabelecidos, não somente pelos valores nutricionais, mas quanto às condições higiênicas que propiciem segurança alimentar e saúde ao consumidor.

\section{Referências}

1. Pecotche CBG. Introdução ao conhecimento logosófico. São Paulo: Logosófica; 2011.

2. Polonio CM. Estresse como modismo. $5^{\circ}$ Mostra Acadêmica UNIMEP; 23-25 out. 2007. Piracicaba, SP: Universidade Metodista de Piracicaba; 2007.

3. Batalha CP, Bueno DS. Reeducação alimentar nas escolas urbanas do município de Lages - SC. UDESC em Ação [Internet] 2010; 4(1). Disponível em: http://www.revistas.udesc.br/index.php/ udescemacao/article/view/2093/pdf_38 
4. Faustino SJ, Passos EC, Mello ARP, Araújo ALM, Souza CV, Jorge LIF, et al. Analises microbiológicas de alimentos processados na Baixada Santista, envolvidos em doenças transmitidas por alimentos, no período de 2000 - 2006. Rev. Inst. Adolfo Lutz 2007; 66(1):26-30.

5. Framegas DPF. Impacto da contaminação de alimentos prontos a comer na Saúde Pública [dissertação]. Aveiro: Universidade de Aveiro, Departamento de Química; 2012.

6. Morgado ASJ. Validação de limites críticos do plano HACCP e avaliação de risco microbiológico num estabelecimento de restauração [Dissertação]. Lisboa: Universidade de Lisboa, Faculdade de Farmácia; 2007.

7. Rodrigues KL, Gomes JP, Conceição RCS, Brod CS, Carvalhal JR, Aleixo JAG. Condições higiênicosanitárias no comércio ambulante de alimentos em Pelotas-RS. Cienc. Tecnol. Aliment. 2003; 23(3):447-452.

8. Santana RF, Santos DM, Martinez ACC, Lima ÁS. Qualidade microbiológica de queijo-coalho comercializado em Aracaju, SE. Arq. Bras. Med. Vet. Zootec. 2008; 60(6):1517-1522.

9. Cardoso ALSP, Tessari ENC, Castro AGM, Kanashiro AMI, Gama NMSQ. Pesquisa de coliformes totais e coliformes fecais analisados em ovos comerciais no laboratório de patologia avícola de descalvado. Arq. Inst. Biol. 2001; 68(1):19-22.

10. Silva, MC. Avaliação da qualidade microbiológica de alimentos com a utilização de metodologias convencionais e do sistema Simplate [Dissertação]. São Paulo: Universidade de São Paulo. Escola Superior de Agricultura “Luis Queiroz”; 2002.

11. Cunha MA. Métodos de detecção de microorganismos indicadores. Saúde \& Ambiente em Revista 2006; 1(1):09-13.

12. Ferreira RS, Simm EM. Análise microbiológica da carne moída de um açougue da região central do município de Pará de Minas/MG. SynThesis Revista Digital Pará de Minas FAPAM [Internet] 2012; 3:3761. Disponível em http://www.fapam.edu.br/revista/volume3/5\%20Rogerio $\% 2038 \% 20$ $-\% 2061 . p d f$

13. Amson GV, Haracemiv SMC, Masson ML. Levantamento de dados epidemiológicos relativos à ocorrências/ surtos de doenças transmitidas por alimentos (Dtas) no estado do Paraná - Brasil, no período de 1978 A 2000. Ciênc. Agrotec. Lavras [Internet] 2006, 30(6):1139-1145. Disponível em http://www.scielo.br/pdf/cagro/v30n6/a16v30n6.pdf

14. Oliveira ABA, Paula CMD, Capalonga R, Cardoso MRI, Tondo EC. Doenças transmitidas por alimentos, principais agentes etiológicos e aspectos gerais: uma revisão. Rev. HCPA [Internet] 2010; 30(3):279-285. Disponível em: http://seer.ufrgs.br/index.php/hcpa/article/view/16422/9805

15. Merussi GD, Maffei DF, Catanozi MPLM. Surtos de gastroenterite relacionados ao consumo de laticínios no estado de São Paulo no período de 2000 a 2010. Alim. Nutr. 202; 23(4)639-645.

16. Forsythe JS. Microbiologia da segurança dos alimentos. Porto Alegre: Artmed; 2013.

17. Silva N. Manual de Métodos de análise microbiológica de alimentos e água. São Paulo: Varela; 2010.

18. Demoliner F, Bierhals I, Fernandes MP, Leal K. Conhecimento de estudantes universitários sobre segurança dos alimentos na cidade de Pelotas, RS. XX Congresso de Iniciação Científica / III 
Mostra Científica, 2011, Pelotas. Disponível em http://www2.ufpel.edu.br/cic/2011/anais/pdf/CS/ CS_00485.pdf

19. Yamaguchi UM, Zanqueta ÉB, Moarais JF, Frausto HSEG, Silvério KI. Qualidade microbiológica de alimentos e de ambientes de trabalho: pesquisa de salmonella e listeria. Revista em Agronegócios e Meio Ambiente 2013; 6(3):417-434. 417-434.

20. Souza LHL. A manipulação inadequado dos alimentos: fator de contaminação. Hig. Aliment. 2006; 20(146):32-39.

21. Brito G. Avaliação da qualidade microbiológica de hambúrgueres e cachorros-quentes comercializados por vendedores ambulantes no município de Juazeiro do Norte, CE. Hig. Aliment. 2003; 17(110):90-94.

22. Pierozan S, Lopes SSAR, Shikida PFA. Avaliação da qualidade higiênico-sanitária de cachorrosquentes comercializados por vendedores ambulantes no lago municipal de Toledo, PR. Arq. Ciênc. Saúde Unipar 2006; 10(1):17-21.

23. Bezerra ACD, Reis RB, Bastos DHM. Microbiological quality of hamburgers sold in the streets of Cuiabá - MT, Brazil and vendor hygiene-awareness. Ciênc. Tecnol. Aliment. 2010; 2(30):520-524.

24. Brasil. Ministério da Agricultura, Pecuária e abastecimento. Instrução Normativa no 83, de 21 de novembro de 2003. Aprova os Regulamentos Técnicos de Identidade e Qualidade de Carnes Bovina em Conserva (Corned Beef) e Carne Moída. Brasília: MAPA; 2003.

25. Manfrin LC. Avaliação da qualidade microbiológica de carne moída bovina comercializada nos supermercados das cidades de Brasília e Taguatinga - DF. [Monografia de Graduação] Brasília: Universidade de Brasília, Faculdade de Ceilândia; 2013.

26. Baptista RIAA, Moura FML, Fernandes MFTS, Santos VVM, Fernandes EFTS. Aspectos qualitativos da carne moída comercializada na região metropolitana do Recife, PE. Acta Veterinária Brasílica [Internet] 2013; 7(1):38-47. Disponível em: http://periodicos.ufersa.edu.br/revistas/index.php/acta/ article/view/3215/5189

27. Leite Júnior BRC, Oliveira PM, Silva FJM, Martins ML. Qualidade microbiológica e alimentos de origem animal comercializados na região de Minas Gerais. Vértices [Internet] 2013; 15(2):4959. Disponível em: http://essentiaeditora.iff.edu.br/index.php/vertices/article/view/1809$2667.20130018 / 2826$

28. Brasil. Associação Nacional de Vigilância Sanitária. RDC nº 216, de 15 de setembro de 2004. Dispõe sobre Regulamento Técnico de Boas Práticas para Serviços de Alimentação. Diário Oficial da União 15 set. 2004. 
